\title{
Erratum to: Evaluation of electrochemical frequency modulation as a new technique for monitoring corrosion and corrosion inhibition of carbon steel in perchloric acid using hydrazine carbodithioic acid derivatives
}

\author{
K. F. Khaled
}

Published online: 28 September 2011

(C) Springer Science+Business Media B.V. 2011

Erratum to: J Appl Electrochem (2009) 39:429-438

DOI 10.1007/s10800-008-9688-y

Unfortunately there were several mistakes in Fig. 2 of this paper. The corrected Fig. 2 is given here.

The online version of the original article can be found under doi:10.1007/s10800-008-9688-y.

K. F. Khaled ( $₫)$

Electrochemistry Research Laboratory, Chemistry Department, Faculty of Education, Ain Shams University, Roxy, Cairo, Egypt

e-mail: khaledrice2003@yahoo.com

K. F. Khaled

Materials and Corrosion Laboratory, Chemistry Department,

Faculty of Science, Taif University, Taif,

Kingdom of Saudi Arabia 

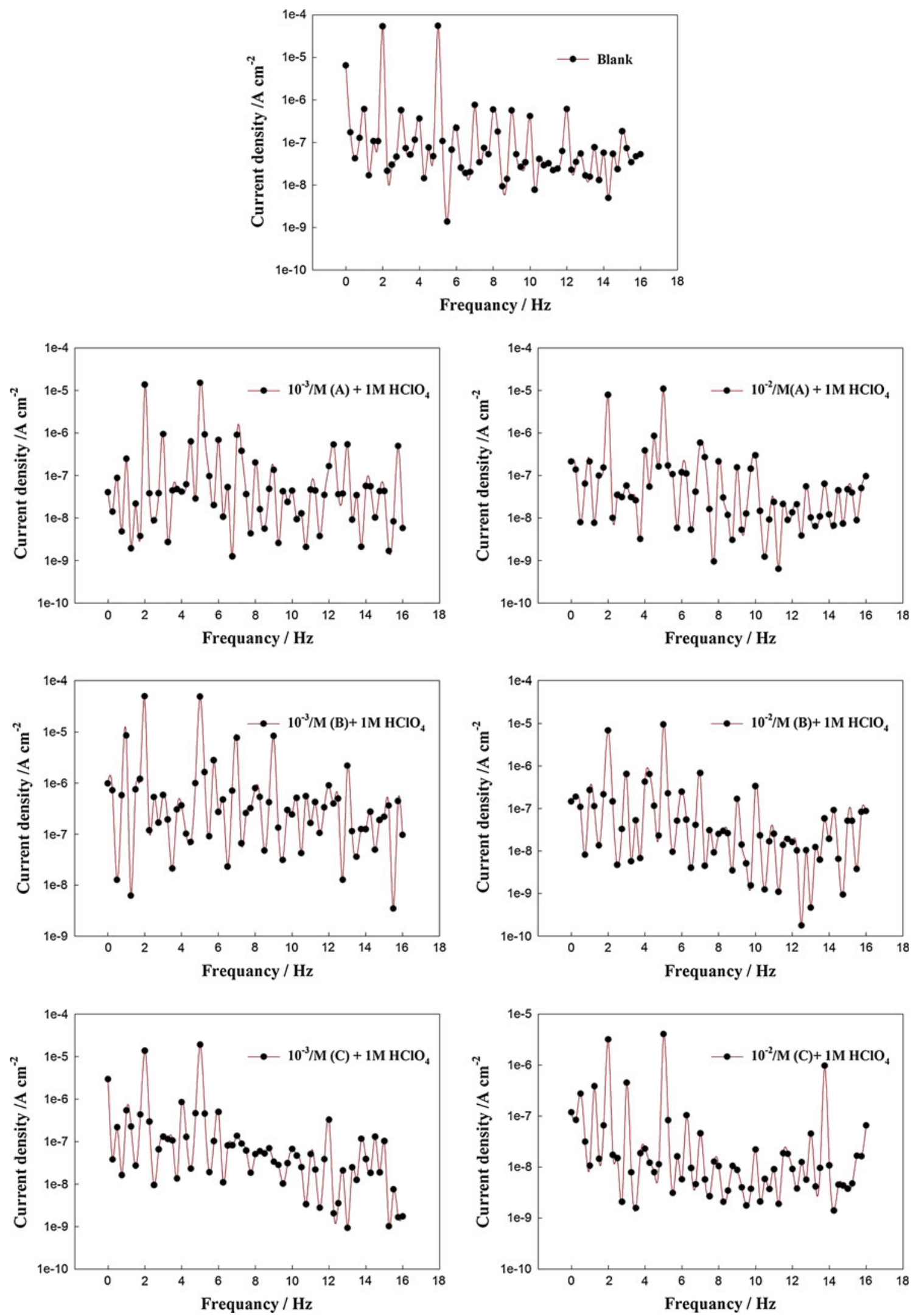

Fig. 2 Intermodulation spectrum for carbon steel in $1 \mathrm{M} \mathrm{HClO}_{4}$ in absence and presence of various concentrations of hydrazine carbodithioic acid derivatives at $25 \pm 1{ }^{\circ} \mathrm{C}$ 